\title{
Representaciones de un sexenio: los memes de Enrique Peña Nieto
}

\author{
Itzel Ruiz Sosa ${ }^{1 *}$, Sergio A. Vargas Matías²*
}

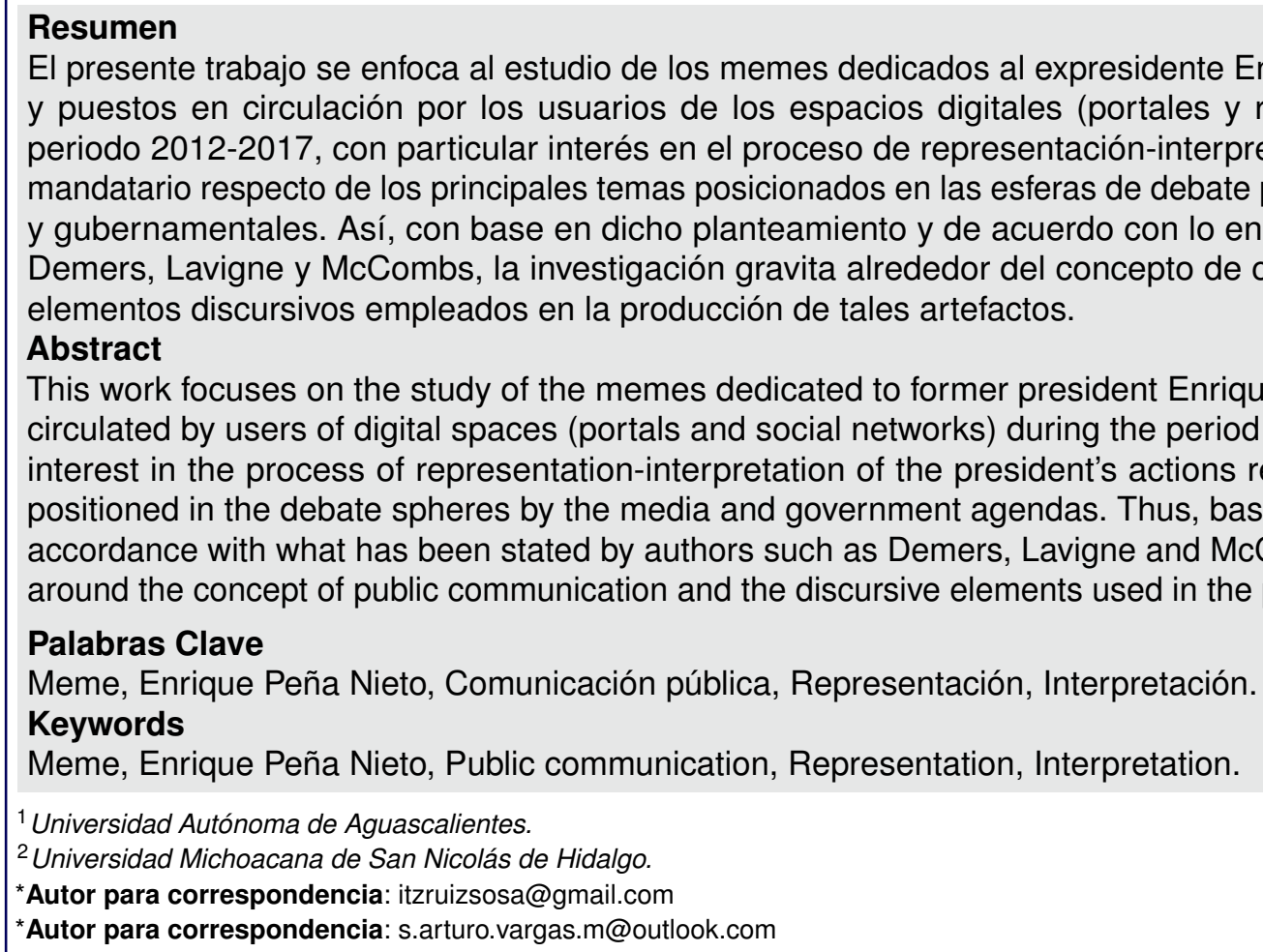

\section{Introducción}

Esta investigación se centra en el estudio de los memes creados y puestos en circulación por los usuarios de los espacios digitales -tales como portales de noticias y entretenimiento, Facebook, Twitter- en México, referentes a la actuación del entonces presidente Enrique Peña Nieto y con relación a los principales temas posicionados en la esfera pública por los entes mediáticos y gubernamentales durante el periodo comprendido entre diciembre de 2012 y noviembre de $2017 .{ }^{1}$

Adhiriéndose a lo enunciado por Hall (1997), es posible englobar tales prácticas -la elaboración y distribución de memes- en los procesos de representación-interpretación y significación que cotidianamente ocurren entre los miembros de aquellos grupos sociales que comparten una cultura y que, por lo mismo, interpretan al mundo de manera similar. Por

\footnotetext{
${ }^{1}$ La periodización de este trabajo estuvo condicionada por la realización de la tesis de maestría de la autora, investigación de la cual se desprende este artículo.
} 
lo tanto, estos expresan sus pensamientos y sentimientos acerca de la "realidad" en formas entendibles para el otro, tal como queda de manifiesto en las prácticas de producción y circulación de los memes, particularmente, en los de tipo político (Shifman, 2014, p. 120).

Aquí conviene recordar que en estos artefactos (los memes de Internet, en adelante simplemente los memes) el sentido se elabora y reelabora constantemente, intercambiándose en cada interacción social, diseminando su contenido velozmente y a gran escala, gracias a la omnipresencia de la tecnologías de información, que propalan sus significados entre individuos de distintos ámbitos, insertándolos en la vida cotidiana, confiriéndoles así un apreciable valor comunicacional (Dawkins, 1976, Dwakins, 2013).

Es posible entender al meme como un sistema de representación que, por medio de determinados elementos visuales y discursivos, se materializa en unos artefactos capaces de transmitir conceptos, ideas o sentimientos y, por ende, de construir sentido y comunicar significado. Así, se puede considerar a los memes como vehículos de sentido, ya que funcionan como entes que expresan los significados que sus creadores pretenden difundir en el espacio público (Hall, 1997).

Partiendo de esa perspectiva, el trabajo está planteado alrededor de las siguientes preguntas:

- ¿Cómo representaron la actuación del presidente Enrique Peña Nieto los usuarios de los espacios digitales en los memes compartidos en Internet?

- ¿Cuáles son los elementos semiótico-discursivos que conforman los memes puestos en circulación por los usuarios de los espacios digitales?

En cuanto al contexto político de México, la investigación se ubica en la etapa que León (2011) denomina como "transición a la democracia" - concepto utilizado con las reservas del caso-. Este se caracteriza por una gran inestabilidad a causa de las transformaciones ocurridas en el sistema político mexicano, sacudido, entre otros factores, por las exigencias de la sociedad civil de una mayor participación política. Lo que lo llevaron al fin de la hegemonía del Partido Revolucionario Institucional (PRI) y permitieron el ascenso al poder de los partidos de oposición en los tres órdenes de gobierno, así como la conformación de congresos plurales en la mayoría de los estados de la república.

\section{El gobierno de Enrique Peña Nieto}

Desde antes de la elección federal del 2012, Enrique Peña Nieto protagonizó una serie de episodios que atrajeron la atención de la prensa y de los usuarios de las distintas plataformas digitales; primero, en la Feria Internacional del Libro de Guadalajara (diciembre de 2011), donde el futuro gobernante fue incapaz de recordar los tres libros que "habían marcado su vida"; después, en mayo de 2012, por su actuación durante su visita a la Universidad Iberoamericana, acontecimiento que tras su difusión en YouTube, desembocó en el movimiento \#YoSoy132.

Una vez electo presidente, Peña Nieto continuó en el centro de la atención de los internautas, tanto por el progresivo deterioro de la situación política, económica y social del país, como por los recurrentes escándalos que ensombrecieron su administración.

Tras iniciar su gobierno con un índice de aceptación del $55 \%$-y un rechazo del $21 \%$ (Parametría, enero de 2013)-, la popularidad del político mexiquense experimentó un declive sostenido, a causa -se infiere- de diversos sucesos, entre los que destacan la desaparición de los 43 estudiantes de la Normal de Ayotzinapa, el escándalo de la "Casa Blanca", la fuga de "El Chapo" Guzmán, las constantes revelaciones de la corrupción de los gobernadores priistas, el "gasolinazo", la visita de Donald Trump a México, y el mal desempeño del mandatario durante su encuentro con Barak Obama y Justin Trudeau, que, en conjunto, lo convirtieron en el presidente peor evaluado de la historia reciente en México.

Lo anterior resulta evidente si se comparan los niveles de aprobación de Peña Nieto durante 2013 -cuando estos se mantuvieron por encima del 50\%-, con los obtenidos entre febrero y noviembre de 2014, periodo en el que sólo entre el $48 \%$ y el $41 \%$ de los mexicanos dijo aprobar "algo" o "mucho" su actuación, según Mitofsky (Huffington Post, 2018). Este descenso se agudizó entre septiembre y noviembre, tras la la desaparición de los "43 de Ayotzinapa" (27 de septiembre de 2014), un hecho que trascendió en el escenario internacional y dejó entrever la violencia imperante en el país y las redes de corrupción existentes entre funcionarios de distintos 
órdenes de gobierno. Asimismo, el declive se reforzó tras la publicación del reportaje "La Casa Blanca", realizado por el equipo de Carmen Aristegui, que dio como resultado un escándalo que encabezó los titulares nacionales y extranjeros.

Todos estos acontecimientos causaron un grave daño en la imagen del mandatario, lo que provocó que, entre los meses de febrero a noviembre de 2015 , el porcentaje de inconformes pasara del $57 \%$ al $65 \%$ (Huffington Post, 2018). Por si fuera poco, el escape de Joaquín "El Chapo” Guzmán de la cárcel de máxima seguridad de El Altiplano, ocurrido en julio de ese año, aumentó el descontento de amplios sectores de la población.

En consecuencia, en 2016 la inconformidad con la administración peñanietista alcanzó el 74\%, según el diario Reforma. Fue uno de los niveles más bajos durante el sexenio y el peor desde 1995, de acuerdo con Huffington Post (2018). Cabe señalar que estas mediciones parecen confirmarse con lo dicho por Mitofsky, recuperado del Huffington Post (2018), que por las mismas fechas reportó niveles de desacuerdo con la gestión presidencial del $69 \%$.

La tendencia a la baja continuó durante el año siguiente, ya que entre febrero y noviembre de 2017, el rechazo al mandatario osciló entre el 71 y el $77 \%$ (Mitofsky). Temas como el espionaje gubernamental a ciertas figuras públicas (el caso Pegasus) y el aumento en los costos de los combustibles, entre otros, posiblemente incidieron en los bajos niveles de aprobación.

En su último año de gobierno, y particularmente durante el período electoral, la impopularidad de Peña Nieto se elevó al $69 \%$. Según un estudio de Mitofsky presentado en Huffington Post (2018), sólo dos de cada 10 mexicanos avalaban la gestión del presidente (21\%). De acuerdo con la encuestadora, el mexiquense era el presidente peor calificado de los últimos cinco sexenios. En consecuencia, al finalizar su periodo, Peña Nieto era repudiado por el $74 \%$ de la población (Huffington Post, 2018).

En vista de lo anterior, conviene reflexionar acerca del papel de los memes como un vehículo representacional de la opinión de un sector de los cibernautas acerca de los asuntos públicos, para cuya creación estos recurren a elementos pertenecientes a ámbitos diferentes -el cine, la televisión, los comics, etc.- de los que usualmente se consideran parte de las esferas de la comunicación política (Wolton, 1998) -los discursos políticos, la información de los medios de comunicación masiva y la opinión pública a través de los sondeos-, reelaborándolos para insertarlos en la discusión pública, usando como estrategia discursiva la sátira y el humor.

Desde esta perspectiva, este trabajo tiene como eje articulador el concepto de opinión pública, por lo que, para los propósitos de esta investigación, resulta pertinente situar las opiniones en un espacio simbólico de participación: el espacio de la comunicación pública (Demers y Lavigne, 2007), el cual se usará a lo largo de este trabajo como un referente que nos servirá para enmarcar teóricamente el objeto de estudio.

\subsection{La comunicación pública como aproximación teórica}

En sintonía con lo antes dicho, habrá que referirse ahora a la noción de esferas públicas, derivada de la comunicación pública, ${ }^{2}$ mismas que Demers y Lavigne definen como un espacio multidimensional donde se intersectan el periodismo, las relaciones públicas, la publicidad y la comunicación en redes (2007, pp. 67-71). Estos autores proponen tres líneas de investigación para el estudio de la comunicación pública: las prácticas profesionales, la intervención social y, finalmente, las representaciones y discursos públicos, vertiente en la cual se inserta este trabajo y que, según ellos:

(...) toma el relevo de una corriente de investigación muy antigua, ya que el análisis de contenidos y de mensajes es practicado desde el inicio de los medios masivos. Se busca el reflejo de las intenciones políticas o ideológicas de los productores, sus estrategias retóricas y discursivas. Se buscan los sentidos escondidos, producidos por estructuras que escapan a la conciencia de los productores, al igual que de los receptores. Se quiere encontrar el reflejo de la sociedad misma y de sus representaciones. (Demers y Lavigne, 2007)

\footnotetext{
${ }^{2}$ El conjunto de los fenómenos de producción, tratamiento, difusión y de retroacción de la información que crea, orienta y transforma los debates y temas públicos. Esta información no solamente es el quehacer de los medios de comunicación, sino también el de las instituciones, las empresas, los movimientos y los grupos que intervienen en la plaza pública (Beauchamp, 1991: XIII, en Demers y Lavigne, 2007).
} 
Al respecto, no está de más recordar que hoy en día, existen nuevas concepciones de la esfera pública debido a la fragmentación de la cultura pública, el aumento de la mediación de los mensajes y el individualismo en las redes sociales; todo lo cual se ve reflejado en una polivocalidad, que enriquece el debate y la participación a través de distintos medios (Milner, 2012, p. 51).

De acuerdo con lo anterior, el Internet podría considerarse, en lo concerniente a los discursos públicos, como un medio participativo y hasta cierto punto, como el estándar de una esfera pública sana (Milner, 2012). Para poder hablar de una democracia en sentido pleno, los ciudadanos deben tener la posibilidad de encontrarse, hablar y compartir opiniones, así como de disponer de contextos que favorezcan la acción colectiva (Dahlgren, 2005, p. 114). No está de más recordar lo dicho por Dalton y Klingmann (Gibson, 2007), quienes sostienen que la democracia está pensada para expresar los intereses de la sociedad, haciéndolos patentes en las decisiones colectivas. Para ello se requiere de una ciudadanía activa, ya que sólo mediante la información y la deliberación es que los intereses de esta pueden identificarse y transformarse en demandas colectivas, por medio de los "hilos políticos" que discurren en el discurso público.

Desde esta óptica, la red constituye un espacio idóneo para el diálogo y la acción ciudadana; favorece la participación en la vida pública de los sectores con menor poder social, brindándoles la oportunidad de irrumpir en la arena política, permitiéndoles visibilizar sus opiniones de manera más fácil que en los medios tradicionales, casi siempre copados por los poderosos. En este sentido, el Internet representa un impulso masivo para los debates en la esfera pública (Milner, 2012, p. 54).

Abundando en lo anterior, es importante destacar que en la actualidad la opinión pública no puede definirse sólo como la suma de las opiniones individuales, el consenso de las mayorías o la expresión pública de los intereses sociales. Por el contrario, debe reconocerse como un "proceso complejo cuya intensidad y multidimensión son intensamente divergentes y hasta antagónicas, además de que sus manifestaciones en los espacios públicos no siempre adquieren la misma significación colectiva" (Meyer, Ahuatzin y Ríos, 2014). Bajo esta nueva concepción:
(...) la opinión pública ha superado paulatinamente la esquematización de una serie de funciones particulares para entenderse como una variada y compleja red de corrientes de valoración y juicio mayormente subjetiva, con múltiples dinámicas y contradicciones y una participación ciudadana cada vez más intensa con mayores espacios para la expresión social. (Meyer, Ahuatzin y Ríos, 2014, pp. 235-237)

Por tanto, desde la perspectiva de las esferas públicas digitales, la opinión pública se explica a partir de dinámicas complejas y diversas. Esto permite analizarla tanto en el heterogéneo terreno de la comunicación mediatizada y el multifacético espacio de las redes cibernéticas, como en las dinámicas sociales, las vivencias individuales y la intersubjetividad colectiva.

Si se asume que la democracia es un régimen basado en la deliberación de los asuntos públicos y el consenso, es imprescindible reconceptualizar la noción de opinión pública para hacerla más compatible con los nuevos enfoques de democracia y ciudadanía, es decir, "no sólo actuar como lugar de representación o decisión, sino también de la participación, la discusión y el enfrentamiento" (Meyer et al., 2014), lo que coincide con lo dicho por Milner (2012) en cuanto a la participación en las redes sociales y otros medios digitales.

La opinión pública puede verse como un componente que va más allá de la democracia representativa para vincularse en su formación, tanto con los procesos de construcción simbólica de las representaciones sociales que realizan los medios masivos de información y las redes de interacción cibernética, como con los espacios públicos de participación, las formas de expresión y manifestaciones ciudadanas, y las distintas manifestaciones culturales y políticas de una sociedad determinada (Meyer et al., 2014).

Cabe recordar que una de las características más sobresalientes de los memes, es su naturaleza intertextual, ya que sus creadores toman elementos de los medios de comunicación dominantes, yuxtaponiéndolas y asociándolas para crear nuevas capas de significado. Si bien muchos memes son básicamente humorísticos, hay un cuerpo creciente de investigaciones que dicen que en ciertos memes están presentes propósitos, motivaciones, e incluso satisfacciones 
más complejas que simplemente provocar risas, pues tienen profundas implicaciones en la construcción de la identidad, el discurso público y el comentario crítico (Milner, 2012, p. 79).

\section{Aproximación metodológica}

Con base en lo anterior, y tomando en cuenta el volumen y la variedad temática de los memes generados durante la administración de Enrique Peña Nieto. Se seleccionó un corpus de memes políticos (Shifman, 2014), derivados -¿inspirados?- de los asuntos que marcaron la agenda mediática (McCombs, 2006) durante el periodo comprendido entre diciembre de 2012 y noviembre de 2017, los cuales circularon de forma reiterada en redes sociales como Facebook, Twitter y portales de noticias y entretenimiento.

Para definir los temas más relevantes en la agenda mediática durante el sexenio peñanietista, se utilizó una metodología sustentada en la herramienta de búsqueda de Google Noticias, con base en períodos trimestrales, enfocada en el nombre del entonces presidente. Obtenidos los resultados, la atención se centró en las primeras tres páginas de estos, donde por lo general aparecían los medios mejor posicionados, como El Universal, Excélsior, Proceso, etc. La pesquisa incluyó discursos oficiales, mensajes a la nación, informes de gobierno, índices de aprobación y, por supuesto, los escándalos que afectaron a la administración pública federal.

Asimismo, se consultaron los recuentos anuales de la administración peñanietista publicados en los principales diarios y portales digitales nacionales como El Universal, Excélsior, Proceso, Aristegui Noticias y Milenio, entre otros, con los que se construyó una tabla con los temas que tuvieron mayor cobertura o fueron más controvertidos, mismos que se verificaron mediante la herramienta Tendencias de Google, para determinar cuáles fueron los que en su momento, encabezaron los asuntos de la agenda.

De esta manera, el diseño metodológico de la investigación se planteó a partir de la pregunta: ¿cómo representaron los usuarios de los espacios digitales la actuación del presidente Enrique Peña Nieto en los memes compartidos en Internet? Tal interrogante definió este trabajo como un estudio descriptivo-interpretativo que se espera, permita inferir la manera en la que los memes participan en la visibilización de ciertos temas de la agenda mediática/gubernamental y cuáles son los elementos semiótico-discursivos que los constituyen.

Se elaboró una metodología de análisis con base en algunas de las teorías y conceptos enunciados por ciertos autores (Hall, 1997, Barthes, 1967 y Jäger, 2003) relacionados con dichas temáticas y otras que consideramos pertinentes para la investigación, como las relacionadas con la opinión pública y el establecimiento de la agenda (McCombs, 2006).

Para la elección de los temas que derivaron en los memes analizados, se partió de la premisa de que las imágenes o asuntos de mayor repercusión expuestos por los principales medios de comunicación del país resultaron particularmente significativos para los públicos de los espacios digitales, quienes los retomaron, re/deconstruyendo su sentido, resignificándolos y codificándolos en forma de memes para luego reinsertarlos en las esferas de debate.

La atención del estudio se enfocó en aquellas imágenes relacionadas con Peña Nieto que, de acuerdo con los resultados arrojados en la búsqueda por tendencias que impactaron de forma más notable en la opinión pública. Cabe señalar que los objetos (McCombs, 2006) elegidos como tema y los memes seleccionados como parte del corpus, poseen características y propiedades que desde nuestro punto de vista, enriquecerían el estudio y facilitarían su análisis por medio de la retórica de la imagen.

Para definir las tendencias noticiosas asociadas con los eventos de mayor impacto, se tomaron en cuenta los sondeos realizados en las fechas que se refieren a lo largo del texto. Así, la elección de los aspectos que podrían resultar más relevantes para el público. Se basó en lo dicho por McCombs (2006) acerca de la agenda de atributos (agenda de los medios/agenda del público) y en los resultados extraídos de las tendencias noticiosas, por mes y año, referentes a los temas de mayor impacto presentes en los espacios digitales.

En la Figura 1, es observable cómo los "picos" más altos corresponden a las fechas en las que las tendencias de búsqueda se centraron en las palabras clave "meme" y "Enrique Peña Nieto", lo que permitió limitar la búsqueda a los memes relacionados con los acontecimientos ocurridos en esos lapsos. 
Tabla 1. Acontecimientos con mayor cobertura periodística durante el sexenio del expresidente Enrique Peña Nieto $(2012-2017) *$

\begin{tabular}{ll}
\hline 2012 & El Pacto por México, Presentación de las reformas estructurales, Reforma educativa \\
& (2012-2013), Movilizaciones magisteriales \\
\hline 2013 & Primer Informe de Gobierno, Reformas [Financiera (2013-2014), Educativa, \\
& Telecomunicaciones (2013-2014) y Energética], Detención de Elba Esther Gordillo, \\
& Liberación de Florence Cassez \\
\hline 2014 & Segundo Informe de Gobierno, Portada Saving México, Ayotzinapa, Manifestaciones \\
& nacionales, \#RenunciaPeñaNieto (ONU Fake News), Reforma de telecomunicaciones, Casa \\
& Blanca Aristegui (2014-2015), Baja el índice de aprobación \\
\hline 2015 & Tercer Informe de Gobierno, Escape/captura de “El Chapo" (2015-2016), Devaluación del \\
& peso, Giras presidenciales, Exoneración Casa Blanca Función pública/disculpas (2015-2016), \\
& Ley General de Transparencia, Artículo El salvador que no lo fue \\
\hline Cuarto Informe de Gobierno, Lo bueno casi no se cuenta, Cumbre líderes en \\
Canadá/manifestaciones maestros y normalistas, Visita de Trump, La caída del peso, Tesis \\
plagiada Aristegui, Javier Duarte, Renuncia Videgaray, Matrimonio igualitario, Caída precios \\
del petróleo, Visita del Papa \\
Quinto Informe de Gobierno, Discurso Gasolinazo, Trump presidente y el muro, Sismo, \\
Regreso de Luis Videgaray, Caso Odebrecht, El socavón (paso express Cuernavaca), Gobierno \\
espía, Mínimo nivel de aprobación, Cumbre G20, Discurso “la crisis en nuestra mente”, \\
Elecciones a gobernador en seis estados, Todo es corrupción
\end{tabular}

*Los medios consultados aparecen en las referencias con el nombre del autor de las notas y artículos revisados.

Fuente: elaboración propia.

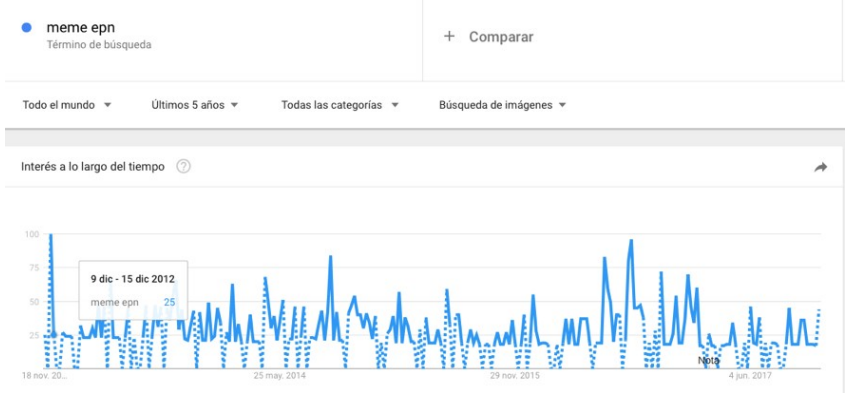

Figura 1. Resultado de tendencia de búsqueda "Meme Peña Nieto y variantes"

Fuente: Google Trends

Posteriormente, se realizó otra búsqueda en Google Trends para precisar en qué meses existía una mayor interacción relacionada con los términos epn, peña nieto, memes y sus variantes. Gracias a esto fue posible elegir los 10 memes correspondientes a los puntos más altos, los cuales se refieren a asuntos como las reformas estructurales, la fuga de El
"Chapo" Guzmán, la visita de Donald Trump y el reportaje de la Casa Blanca.

Dichos memes fueron compartidos en los portales de los medios digitales con mayor penetración -Aristegui Noticias, Sinembargo, Sopitas, etcétera-, quienes probablemente los sustrajeron de las redes sociales; de la misma manera, las audiencias de estos medios retomaron tales memes para distribuirlos -e incluso reinterpretarlos- a través de sus propias redes sociales.

\section{El análisis crítico del discurso en la propuesta metodológica}

Para el análisis de los memes que conforman el corpus de la investigación, se consideraron distintas herramientas, entre ellas, el Análisis Crítico del Discurso (ACD), técnica que de acuerdo con Wodak y Meyer (2003), se enfoca en el estudio del lenguaje como práctica social, así como en las relaciones de dominación, discriminación, poder y control, que se manifiestan a través de este. Asimismo, el ACD pretende analizar - de forma crítica- la desigualdad social 
tal como es expresada, señalada, constituida, legitimada, etc., por los usos del lenguaje, es decir, por el discurso (pp. 18-19).

Por consiguiente, son tres los conceptos que sin excepción figuran en todo ACD: poder, historia e ideología. Un aspecto importante que resulta de la asunción del ACD es la idea de que todos los discursos son históricos y por consiguiente sólo pueden entenderse con relación a su contexto (p. 37).

En este punto es pertinente mencionar que el interés por esta herramienta se explica en el trabajo realizado por Milner (2012), quien la aplicó a los memes derivados de una serie de conflictos sociales con el propósito de dilucidar las conexiones entre textos, discursos e identidades, enfocándose en aspectos como la intertextualidad (textos que refieren a otros textos), la interdiscursividad (discursos en otros discursos) y lo multimodal (palabras, imágenes y sonidos).

Cabe agregar lo dicho por Reisigl y Wodak (Milner, 2013), quienes sostienen que la intertextualidad y la interdiscursividad son el puente mediante el cual un discurso puede ser recontextualizado y transferido de un escenario a otro para crear una yuxtaposición, producir una metáfora o postular una verdad universal (p. 2363).

Por tanto, en este trabajo se incorpora los conceptos de intermedialidad y transmedialidad al método de Milner (2012) para estudiar la relación entre los asuntos seleccionados de la agenda de la administración pública federal vigente y la información que de esta difundieron los principales medios de comunicación, así como aquellos elementos retomados del cine, la televisión, el cómic, la música, la publicidad, entre otros medios y plataformas que en síntesis, participan en la elaboración de los memes objeto de estudio.

Aquí resulta oportuno recordar que "el meme es una representación multimodal con ‘algo’ más que palabras, que proyecta una ideología de manera visual y sutil" (Milner, 2012, p. 81). Por lo que el ACD es una metodología pertinente para el análisis de estas unidades de replicación cultural, ya que si bien la ideología del productor (o de quien comparte el meme) por lo general no se enuncia de forma directa, sí aparece implícita, lo que significa una oportunidad para comprender el funcionamiento de los textos y los discursos en múltiples niveles, apreciando su lógica y su estética, siendo estos actos comunicativos una muestra de la cohesión entre lo verbal y lo visual, donde texto, imagen, sonido, video e hipervínculo pueden coexistir en un mismo plano comunicativo.

\section{El análisis de los memes en la esfera pública digital}

Por otra parte, hay que señalar además, que los memes son una herramienta útil para entender los efectos de la participación cultural "mediada" en la esfera pública (Habermas), en concordancia con su concepción original como un espacio en el que los ciudadanos deliberan sobre los asuntos políticos y sociales, es decir, un espacio comunicativo tal como aquellos lugares físicos -bares o cafeterías- o metafóricos -las páginas de los diarios- en los que hasta hace pocos años se discutían los temas de interés común (Milner, 2012, p. 50).

Desde esta óptica, es posible estudiar los elementos utilizados por los medios masivos para exponer la imagen de Enrique Peña Nieto ante las audiencias en conjunto con los agregados por los usuarios de las redes sociales, quienes entretejieron ambos discursos y los reconfiguraron para crear nuevos significados; considerando los puntos anteriores, fue posible diseñar una estrategia de análisis que nos permitió hacer una mejor y más precisa aproximación al objeto de estudio, proceso cuya operacionalización se explica en la tabla siguiente:

- Representación de la agenda mediática: se refiere a los elementos que integran el meme. En el proceso de significación hay dos sistemas relacionados con la representación: El primero, nos permite dar sentido mediante un conjunto de correspondencias/equivalencias entre las cosas y nuestro sistema de mapas conceptuales.

El segundo, depende de la construcción de un conjunto de signos ordenados que representan los conceptos. La relación entre conceptos y signos produce sentido; el proceso que vincula esos tres elementos es lo que llamamos “representación” (Hall, 1997, pp. 19-20). Con base en lo anterior, se pretende identificar los vínculos de sentido entre lo expuesto en la agenda mediática y gubernamental y lo representado en los memes, es decir, el objeto/persona/evento correlacionado. 
Tabla 2. Análisis de la imagen en los discursos y medios

\begin{tabular}{ll}
\hline Representación de la agenda mediática & $\begin{array}{l}\text { Sistemas de representación y producción de } \\
\text { significado }\end{array}$ \\
\hline Descripción de la imagen en los discursos y medios & Intertextualidad \\
& Interdiscursividad \\
& Intermedialidad \\
& Transmedialidad \\
\hline Estructura del discurso & Acontecimientos discursivos y contexto Códigos \\
& retóricos de la imagen: Denotación y connotación \\
\hline
\end{tabular}

- Descripción de la imagen en los discursos y medios: en este apartado recurrimos a conceptos como el de intertextualidad, acuñado por Julia Kristeva en la década de 1960 - a partir de lo dicho por Bakhtinquien a grandes rasgos, sostiene que "el sentido de un texto se construye por medio de referencias a otros textos" (Pérez, 2017, p. 112), y en el caso que nos ocupa, con alusiones a ciertos discursos mediáticos a través de la intermedialidad, la transmedialidad y la interdiscursividad (Scolari, 2014) mediante los cuales se construye (o reelabora) una imagen "creativa" que representa una extensión o reescritura del discurso en otro medio.

- Estructura del discurso: aquí, se propone un análisis basado en dos aspectos fundamentales: los acontecimientos discursivos y el contexto. Los acontecimientos discursivos son aquellos en los que hay un especial énfasis político, es decir, han sido abordados por los medios de comunicación y se enmarcan en el contexto con el que se relaciona el hilo discursivo vigente, entretejiéndose para construir nuevos significados en torno a la imagen (Jäger, 2003).

Para completar el proceso de representación, es necesario un código básico que enlace "la cosa" (significante) con nuestro concepto mental de ella (significado) con Hall (1997); de ahí, es posible avanzar a un segundo nivel, más amplio y profundo, donde se entrelazan temas, conceptos y significados culturales, para cuyo análisis son útiles los conceptos de denotación y connotación, por medio de los cuales es posible discernir lo que podríamos llamar campos semánticos de nuestra cultura, a través del análisis retórico de la imagen (Barthes, 1967).

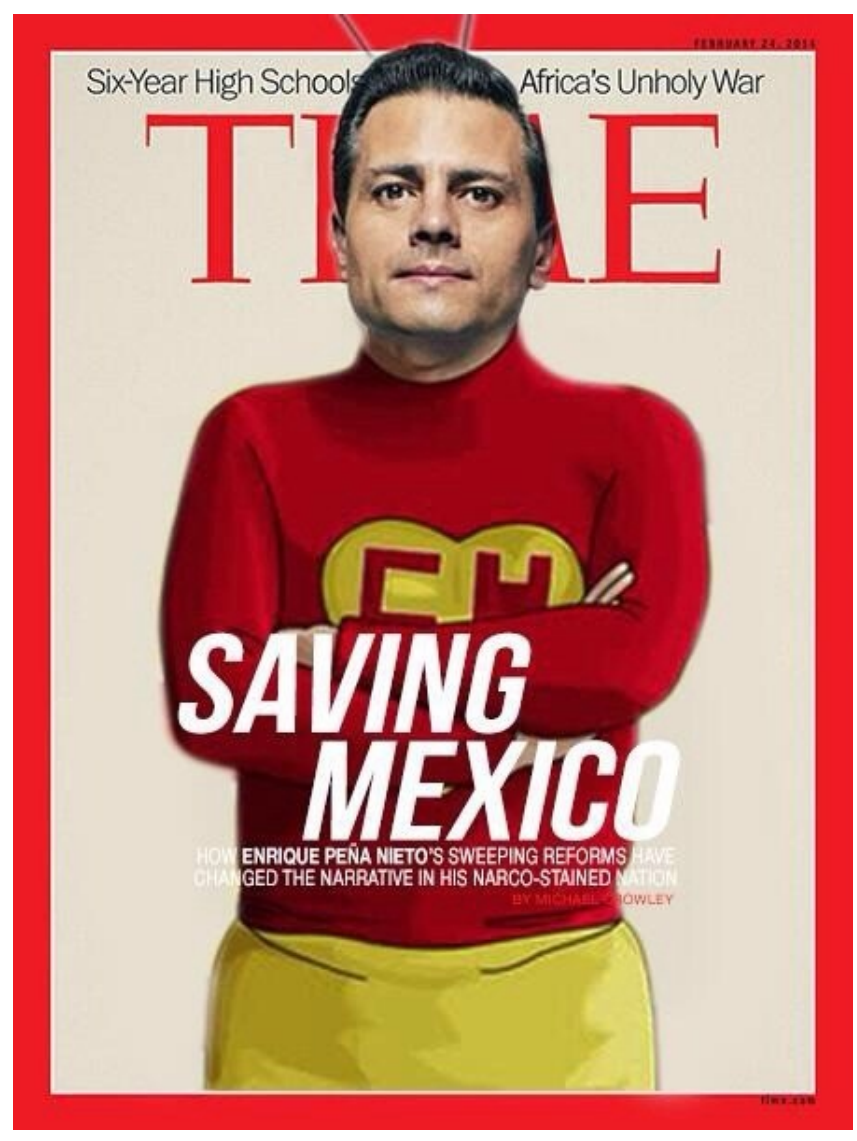

Figura 2. Meme "Saving Mexico"

Tipología: holomeme

Fuente: imagen recuperada de espacios digitales

\section{La agenda mediática}

- Firma del Acuerdo Multilateral de Libre Comercio, en la VIII Cumbre de la Alianza del Pacífico, convenio que según el presidente Peña contribuiría a la generación de empleos, así como a un mayor flujo comercial. 
- Publicación del Índice de Desempleo correspondiente al primer año del gobierno peñanietista, según cifras de la Organización para la Cooperación y el Desarrollo Económico (OCDE).

- Aprobación en el Senado de la Ley de Antiterrorismo, la cual preveía hasta 40 años de cárcel a quienes cometieran hechos violentos en el transcurso de una "marcha” en el país.

- Controversia ligada al conflicto Televisa-Dish, en la que la Presidencia de la República interpuso una controversia legal ante la Suprema Corte de Justicia de la Nación (SCJN) en contra el Juez 32 de lo Civil de la Ciudad de México, por invalidar las facultades constitucionales del Instituto Federal de Telecomunicaciones (IFT) para resolver sobre la retransmisión gratuita en la televisión de paga de los contenidos de la televisión abierta (must carry y must offer).

- Hallazgo de un narcotúnel subterráneo que conectaba la ciudad de Nogales (Sonora) con Arizona.

\section{La imagen en los discursos y medios}

- Revista Time: el 13 de febrero de 2014 este medio anunció que el presidente mexicano aparecería en la portada de su edición del día 24, y dio a conocer un extracto del reportaje escrito por Michael Crowley. De acuerdo con $C N N$, en la publicación se destacaba cómo las reformas estructurales habían cambiado la percepción de un país manchado por la violencia del crimen organizado. El reportaje titulado "Saving Mexico" (Salvando a México), explicaba que las quejas por los ataques del narcotráfico y el mal estado de la economía del país, estaban siendo remplazadas por aplausos. En la entrevista realizada al mandatario, Crowley describía al mandatario como un joven reformador con las cualidades necesarias para estimular el desarrollo del país.

Unos días después, el periódico El País (2014) informó que la portada de Time había causado una gran polémica entre los mexicanos, particularmente en las redes sociales. Según El País, la revista había publicado la entrevista con Peña Nieto en sus ediciones para Europa, Oriente Próximo, África, Asia y el Pacífico Sur pero no en Estados Unidos, lo que fue muy criticado por los usuarios de Facebook y Twitter, quienes opinaban que el texto no reflejaba la realidad de México y calificaron la aparición Peña Nieto como una operación de relaciones públicas organizada por el gobierno mexicano.

- El Chapulín Colorado: personaje de la televisión mexicana creado por Roberto Gómez Bolaños "Chespirito", como una parodia de los superhéroes estadunidenses de Marvel y DC Comics. El programa fue transmitido por primera vez en México en 1970. El periódico argentino La Nación, en su edición digital del 15 de septiembre de 2013, describió al personaje como un héroe atípico, miedoso, torpe y lento que, invariablemente, ocasionaba más problemas de los que solucionaba.

\section{Estructura del discurso}

Como puede verse en el punto 1, la aparición de Peña Nieto en Time coincidió con numerosos hechos noticiosos en México, la mayor parte de ellos negativos, lo que contrastaba notablemente con la información contenida en el reportaje publicado en la revista; esto provocó numerosos memes entre los que destaca el que hemos titulado "Saving México", cuyo análisis presentamos a continuación: 
Tabla 3. Análisis retórico

\section{DENOTACIÓN}

\section{Imagen}

Enrique Peña Nieto aparece en la portada de la revista Time disfrazado como El Chapulín Colorado, personaje de la televisión mexicana, con los brazos cruzados y mirando fijamente a la cámara.

\section{Texto}

SAVING MEXICO

How Enrique Peña Nieto's sweeping reforms have changed the narrative in his narco-stained nation

\section{Imagen}

En este meme, EPN aparece en la portada de la revista Time caracterizado como el Chapulín Colorado, personaje cómico creado por Roberto Gómez Bolaños, con la frase que da título al artículo principal de la publicación yuxtapuesto en su persona. La vestimenta del Chapulín Colorado remite de manera paródica a la idea de EPN como un "héroe" que va a salvar a México, si bien como lo dijo Gómez Bolaños, el Chapulín es personaje diferente a los de Marvel o DC Comics, poderosos y casi siempre capaces de vencer cualquier obstáculo; por el contrario, el Chapulín es un héroe sin mayores poderes que su "chipote chillón" y sus pastillas de "chiquitolina", torpe, débil, poco inteligente y cobarde, que en muchas ocasiones provoca más problemas que los que resuelve, si bien por lo general termina por vencer sus miedos y consigue hacer el bien.

\section{Texto}

En este caso, la frase "Saving México" tomada del artículo escrito por Michael Crowley, constituye una burla a lo dicho por este acerca de las reformas estructurales puestas en operación por EPN, que según el autor, representaban un cambio en "la narrativa de un país manchado por el narco"; por el contrario, en el meme, la frase y la imagen muestran a un héroe muy poco confiable, incapaz de salvar a México.

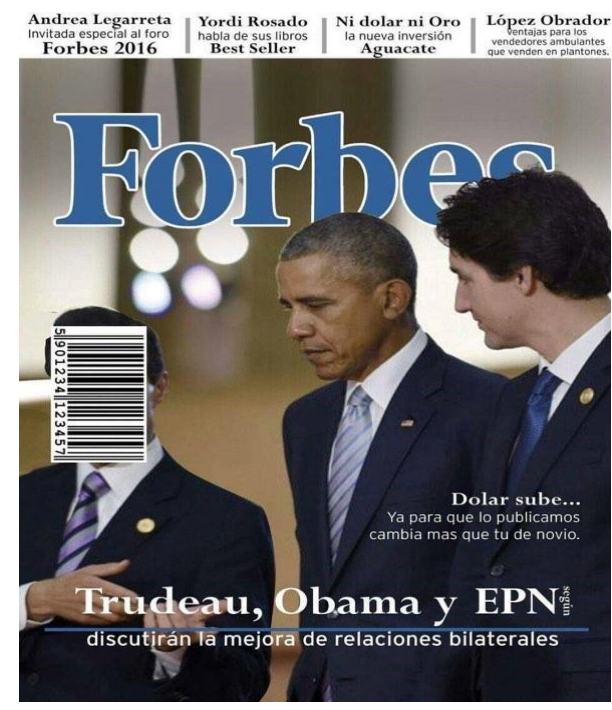

Figura 3. Meme "EPN en Cumbre Líderes de América"

Tipología: holomeme Fuente: recuperada de espacios digitales

\section{Representación de la agenda mediática}

De acuerdo a la revisión de las noticias y tendencias aparecidas en Google en el periodo del 20 de junio al 2 de julio de 2016, los temas publicados por los principales diarios del país de forma paralela a la aparición del meme referido, fueron los siguientes:

- Gira internacional de Peña Nieto, incluida una estancia en Canadá, donde participaría en la Cumbre Líderes de América del Norte al lado de Barack Obama, entonces presidente de los Estados Unidos y Justin Trudeau, Primer Ministro de Canadá.

- Los padres de los 43 normalistas desaparecidos en Iguala denuncian intimidaciones; la Coordinadora Nacional de Trabajadores de la Educación (CNTE) se incorpora a las movilizaciones en protesta por los “43 de Ayotzinapa”. Los padres de los estudiantes desaparecidos marchan por Paseo de la Reforma acompañados de los representantes de la CNTE. 
- El Secretario de Gobernación Miguel Osorio Chong pide a la CNTE que retire los bloqueos impuestos por esa organización en varias carreteras del sur del país.

- Críticas por el mal desempeño de Peña Nieto durante su encuentro con Justin Trudeu y Barak Obama.

- Aumento de las tasas de interés en México como respuesta a la caída del peso frente al dólar causada por la incertidumbre internacional, la atonía económica y el creciente ascenso de Donald Trump en las encuestas presidenciales.

\section{La imagen en los discursos y medios}

- Participación del presidente Peña participa en la VIII Cumbre de Líderes de América del Norte.

- Monsters Inc. es una película animada producida por Pixar Animation Studios en 2001, dirigida por Pete Docter. La cinta cuenta las peripecias de dos monstruos, James P. "Sulley" Sullivan y Mike Wazowski, quienes trabajan en la empresa Monsters, Inc., dedicada a producir energía, la cual genera asustando a los niños humanos. En la trama, una pequeña entra en la fábrica por descuido de los protagonistas y estos deben regresarla a casa antes de que sea descubierta.

En la película, hay una escena donde "Sulley" y Mike aparecen en la portada de la revista Business Shrick, gracias al éxito del primero, quien es el principal "asustador" de la empresa. En dicha portada Mike apenas se reconoce, pues su cara es cubierta por un código de barras.

- Andrea Legarreta: actriz mexicana y conductora del popular programa Hoy que a principios de 2016, fue trending topic por sus declaraciones acerca de la depreciación del peso ante el dólar: "El que suba el dólar no afecta a los mexicanos. Sube por culpa de las economías de otros países que están mal. No es por culpa de nuestro gobierno". Estas afirmaciones provocaron una ola de burlas en Twitter, y generaron numerosos comentarios críticos aludiendo el escaso conocimiento de la actriz en materia económica.

- Yordi Rosado: conductor, productor, locutor y escritor mexicano, autor de varios libros dirigidos al público adolescente (Quiúbole con...) que en conjunto han vendido más de 2.5 millones de ejemplares.

- El aguacate mexicano: en junio de 2016, el precio de este fruto aumentó en un $90 \%$, según el portal de la revista Expansión.

- Andrés Manuel López Obrador: en aquel momento, la figura del hoy presidente había logrado una gran relevancia mediática a causa de sus pronunciamientos en contra de los aumentos al precio de las gasolinas, la dura respuesta dada por Barak Obama a Enrique Peña Nieto durante la Cumbre de Líderes de América del Norte por las críticas de este al populismo; así como por las fuertes críticas del líder de Morena al entonces Secretario de Gobernación, Miguel Osorio Chong por las acciones del gobierno federal a los bloqueos carreteros efectuados por el movimiento magisterial como respuesta a la puesta en marcha de la reforma educativa.

\section{Estructura del discurso}

\section{Consideraciones finales}

$\mathrm{Si}$ bien resulta complicado elaborar conclusiones definitivas en torno de un campo de estudio que como el meme todavía está en construcción, es posible inferir algunas premisas en cuanto a sus procesos de producción, circulación y apropiación. En primer término podemos afirmar con las reservas del caso, que el meme constituye un medio de expresión con características particulares que lo emparentan e insertan en una larga tradición de manifestaciones subersivas y/o alternativas de la opinión pública, como podrían ser el cartel, el graffiti y la caricatura política, con los que comparte rasgos comunes como la consición, el humor, la crítica y el simbolismo. No obstante, dada la dificultad de identificar a los productores de estos artefactos, debe matizarse su naturaleza contestataria, ya que el anonimato de su producción favorece que estos elementos puedan ser usados por los poderes establecidos y fácticos para transmitir mensajes con intenciones de favorecer el status quo, o bien, busquen denigrar, tergiversar o falsear los emitidos por los sectores críticos u opuestos a dichos poderes. 


\section{DENOTACIÓN}

\section{Imagen}

Tres hombres (EPN, Barak Obama y Justin Trudeau) aparecen en la portada de Forbes. Todos visten traje y corbata y tienen un pin dorado del lado izquierdo de la solapa del saco. En la parte inferior izquierda, está el de menor estatura, con el rostro tapado por un código de barras que sólo deja ver su cabello. Por la posición de sus manos se infiere que platica con los otros dos.

Junto al primer sujeto aparece otro que dirige su vista hacia abajo. En el extremo derecho se observa al sujeto más alto de los tres, quien observa con atención al personaje de en medio. El fondo de la fotografía se muestra difuminado.

\section{CONNOTACIÓN}

\section{Imagen}

El meme simula una portada de la revista Forbes en la que aparecen los mandatarios de Estados Unidos, Barak Obama; Canadá, Justin Trudeau; y México, Enrique Peña Nieto, quien únicamente se reconoce por su característico copete, ya que su rostro está tapado por el código de barras de la revista. Obama y Trudeu parecen mirar a EPN quien gesticula con las manos. La imagen se complementa con varios "llamados" que remiten al contenido que supuestamente encontrará el lector en las páginas interiores. La supresión de la cara de EPN es una metáfora que alude a su "desaparición” frente a sus pares, debido a. su errático desempeño durante la reunión que sostuvo con ellos en Ottawa, lo que motivó la creación de numerosos memes y caricaturas que ridiculizaban al mexicano y enfatizaban la supuesta superioridad intelectual de Obama y Trudeau, así como su cercana relación en contraste con el trato cordial pero distante que ambos manifestaron en su interacción con EPN, como fue evidente en el multicitado episodio en el que Obama y Trudeau ceden el paso al presidente mexicano y luego se quedan admirando el paisaje de Ottawa, olvidándose del mexicano, quien se ve forzado a regresar para tratar de integrarse a la charla.

Texto
En el cintillo superior aparecen tres llamados
(se respeta el estilo): "Andrea Legarreta invitada
especial al Foro Forbes 2016" / "Jordi Rosado
habla de sus Best Seller" / "Ni dólar ni Oro la nueva
inversión Aguacate" / "López Obrador ventajas
para los vendedores ambulantes que venden en
plantones". En el medio, aparece otro llamado que
dice: "Dólar sube... Ya para que lo publicamos
cambia más que tu de novio". Finalmente, la nota
principal de la revista se titula: "Trudeau, Obama y
EPN discutirán la mejora de relaciones bilaterales
según".
Texto

La participación de Andrea Legarreta en el Foro Forbes es una alusión irónica al escaso conocimiento de la conductora en materia económica. En cuanto a Yordi Rosado, es un comentario sarcástico por su condición de autor de libros muy vendidos pero de escasa calidad. Con relación al aguacate, se refiere al alza que tuvo el precio de este fruto por las fechas en que apareció el meme. El texto que menciona a López Obrador, se refiere a que sus constantes protestas brindaban oportunidades de negocio a los vendedores ambulantes. La mención al dólar hace referencia a un nuevo aumento del valor de esta moneda. Finalmente, el encabezado de la revista alude al encuentro entre los mandatarios norteamericanos, reunión que a pesar de la expectación levantada, no prometía demasiados resultados.
Por otra parte, si bien su viralidad $-\mathrm{y}$ su brevedad vital- no garantiza de modo alguno un impacto medible y/o duradero en la opinión pública, desde nuestro punto de vista, es válido asumir que en ciertos casos, su mayor o menor replicación/apropiación/circulación, puede considerarse como un indicador de su incidencia en la discusión de los asuntos públicos, así como del sentir de ciertos sectores de los usuarios de las redes sociales con respecto a los temas presentes en la agenda mediática.

En el caso que nos ocupa, es evidente que los memes dedicados a la actuación de Peña Nieto, pueden considerarse como un vehículo de expresión usado por un amplio sector de los usuarios de los espacios digitales para hacer patente su descontento y/o inconformidad con el desempeño de uno de los personajes más cuestionados en México en las últimas tres décadas. En este sentido, los memes funcionaron también como un elemento de contraste frente al discurso prevaleciente en los medios tradicionales, especialmente durante los dos primeros años de la administración peñanietista, cuando tras la firma del Pacto por México, el presidente mexicano había logrado posicionarse como un reformador eficiente y un político eficaz.

Al respecto, es claro que a diferencia de lo ocurrido en México durante el régimen priista, cuando la televisión comercial -estrechamente ligada al gobierno- y la prensa escrita dominaban el discurso en las esferas de debate -lo que permitía un control efectivo de la información que llegaba al público-, en la actualidad, las redes sociales han 
abierto una brecha irreparable en las políticas de control de información y censura que prevalecieron durante el siglo pasado, permitiendo un flujo de comunicación imposible de controlar por parte de los poderes del Estado, lo que ha obligado a los medios tradicionales a adoptar una postura no tan oficialista o cuando menos, más plural en el tratamiento de los asuntos públicos.

Por otra parte, es evidente que el fenómeno del meme no puede explicarse sin la confluencia, sincretismo o yuxtaposición de los distintos elementos de la cultura popular y mediática, coincidencia posible gracias a la transmedialidad, la intermedialidad, la interdiscursividad y el anonimato inherentes a la world wide web. En este sentido, el estudio de estos artefactos puede verse beneficiado en el corto plazo, con el uso de las herramientas propias de los análisis cuantitativos, como el Big Data, y la profundización en la "disección" de los elementos ocultos que subyacen en los distintos niveles de significado contenido en ellos, por ejemplo, a través de estudios de tipo inconográfico e iconológico (Panofsky) y la comprensión de las estrategias de manipulación -intencionales o no- empleadas en su confección (Greimas).

\section{Referencias}

Ayala, F. (2 de septiembre de 2015). Los 10 momentos que han marcado el gobierno de Peña Nieto Publimetro México. Recuperado de https://www.publimetro.com.mx/mx/not icias/2015/09/02/10-momentos-que-han-marcado-gob ierno-pena-nieto.html

Barthes, R. (1967). The elements of semiology. London, England.: Cape.

Beauregard, L. (2 de febrero de 2014). La revista "Time" causa polémica con una portada de Peña Nieto I Internacional I EL PAÍS. Recuperado de https://elpais.com/internaci onal/2014/02/14/actualidad/1392416289_721957.html

Dahlgren, P. (2005). The Internet, public spheres, and political communication: Dispersion and deliberation. Political Communication, 22, 147-162.

Dawkins, R. (1976). The selfish gene (O. U. Press Ed. 30 ed.). Nueva York, Estados Unidos: Oxford.

Demers, F., \& Lavigne, A. (2007). La comunicación pública: una prioridad contemporánea de investigación. Comunicación y sociedad, 7, 87.

El Universal. (1 de diciembre de 2015). Presidencia destaca logros a 3 años de gobierno de EPN. Recuperado de http://www.eluniversal.com.mx/articulo/nacion/politic a/2015/12/1/presidencia-destaca-logros-3-anos-de-g obierno-de-epn

García, J. L. (21 de febrero de 2017). El gasolinazo, un peso aporreado y la debilidad ante Trump hunden a Peña en todas las encuestas. Recuperado de https://www.sinemb argo.mx/21-02-2017/3157474

Gibson, J. L. (2007). Political intolerance in the context of democratic theory. In R. J. Dalton \& H.-D. Klingemann (Eds.), The Oxford Handbook of Political Behavior (323-341). Oxford, UK: Oxford University Press.

Hall, S. (1997). The work of representation. En Representation: cultural representations and signifying practices. London, England.: SAGE Publications Ltd.

Jäger, S. (2003). Discurso y conocimiento: aspectos teóricos y metodológicos de la crítica del discurso y del análisis de dispositivos. In Gedisa (Ed.), Métodos de análisis crítico del discurso. España.

León, S. (2011). Comunicación pública, transición política y periodismo en México: el caso de Aguascalientes. Comunicación y sociedad. 15, 43-69.

McCombs, M. (2006). Estableciendo la agenda. El impacto de los medios en la opinión pública y en el conocimiento. Barcelona, España: Paidós Ibérica.

Meyer, J., Ahuactzin, C., \& Ríos, C. (mayo, 2014). Democracia y opinión pública en el contexto de la posmodernidad. Trabajo presentado en el Encuentro Nacional de la Asociación mexicana de Investigadores de la Comunicación A.C. San Luis Potosí, México.

Milner, R. (2012). The world made meme: discourse and identity in participatory media. (Tesis doctoral inédita), University of Kansas, Estados Unidos.

Milner, R. (2013). Pop Polyvocality: Internet Memes, Public Participation, and the Occupy Wall Street Movement. International Journal of Communication 7, 2357-2390

Pérez, G. (2017). El meme en Internet. Identidad y usos sociales Coahuila, México.: Universidad Autónoma de Coahuila. Editorial Fontamara

Redacción (25 de noviembre de 2018). La caída de un presidente. EPN termina su sexenio con 74 porciento de desaprobación. Recuperado de https://www.huffington post.com.mx/2018/11/25/la-caida-de-un-presidente-e pn-termina-su-sexenio-con-74-de-desaprobacion_a_2 3599774/?fbclid=IwAR3MbsrP91xbi-rEnlq624o45iTy 6Miv3JfwJ0K3i3SsjIX220y9JNpMOYE

Rojas, J. (2013). Los buenos aún siguen al Chapulín Colorado - La Nación. Recuperado de https://www.nacion.com/v iva/television/los-buenos-aun-siguen-al-chapulin-col orado/2EBTY4V72NA5DMW5N6L5IRHDGU/story/

Santana, J., \& Smith, X. (Producer). (2013). Just for Hits. Richard Dawkins. Recuperado de https://www.youtub e.com/watch?v=GFn-ixX9edg\&list=PLgm8GJS8fU6 _MdO1SRzUBOefp4hA27sXZ\&index=1

Scolari, C. A. (2014). Lostología. Narrativa transmediática, estrategias crossmedia e hipertelevisión. En Narrativas 
transmedia entre teorías y prácticas. Barcelona, España.: Editorial UOC.

Shifman, L. (2014). Memes in digital culture. Cambridge, Massachusetts: The MIT Press.

Wodak, R., \& Meyer, M. (2003). Métodos de análisis crítico del discurso. Barcelona, España.: Gedisa.

Wolton, D. (1998). La comunicación política: construcción de un modelo. En El nuevo espacio público. Barcelona, España: Gedisa, S.A. 